Check for updates

Cite this: J. Mater. Chem. A, 2018, 6, 10507

Received 20th March 2018 Accepted 10th May 2018

DOI: $10.1039 / \mathrm{c} 8 \mathrm{ta0} 2601 \mathrm{~g}$

rsc.li/materials-a

\section{The synthesis, chain-packing simulation and long-term gas permeability of highly selective spirobifluorene-based polymers of intrinsic microporosity $\dagger$}

\author{
C. Grazia Bezzu, (D) a Mariolino Carta, (DD ${ }^{\mathrm{b}}$ Maria-Chiara Ferrari, ${ }^{\mathrm{c}}$ \\ Johannes C. Jansen, (D) d Marcello Monteleone, (DD ${ }^{d}$ Elisa Esposito, (D) d

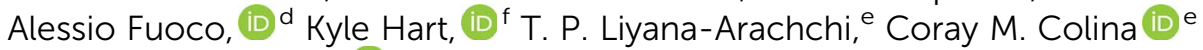 \\ and Neil B. McKeown (D) *a
}

\begin{abstract}
Membranes composed of Polymers of Intrinsic Microporosity (SBF-PIMs) have potential for commercial gas separation. Here we report a combined simulation and experimental study to investigate the effect on polymer microporosity and gas permeability by placing simple substituents such as methyl, $t$-butyl and fused benzo groups onto PIMs derived from spirobifluorene (PIM-SBFs). It is shown that methyl or t-butyl substituents both cause a large increase in gas permeabilities with four methyl groups enhancing the concentration of ultramicropores $(<0.7 \mathrm{~nm})$, which contribute to selective gas transport. The $t$-butyl substituents lower selectivity by generating a greater concentration of larger, less selective, micropores (>1.0 nm). Long-term ageing studies (>3.5 years) demonstrate the potential of PIM-SBFs as highperformance membrane materials for gas separations. In particular, the data for the PIM derived from tetramethyl substituted SBF reaches the proposed 2015 Robeson upper bound for $\mathrm{O}_{2} / \mathrm{N}_{2}$ and, hence, hold promise for the oxygen or nitrogen enrichment of air. Mixed gas permeation measurements for $\mathrm{CO}_{2} / \mathrm{CH}_{4}$ of the aged PIM-SBFs also demonstrate their potential for natural gas or biogas upgrading.
\end{abstract}

\section{Introduction}

Polymer membranes are used commercially for the efficient separation of gases such as oxygen or nitrogen enrichment of air (i.e. $\mathrm{O}_{2}$ from $\mathrm{N}_{2}$ ), natural gas and biogas upgrading (i.e. predominantly $\mathrm{CO}_{2}$ from $\mathrm{CH}_{4}$ ) and for hydrogen recovery during ammonia preparation $\left(\mathrm{H}_{2}\right.$ from $\left.\mathrm{N}_{2}\right) \cdot{ }^{1-4}$ Recently, their potential for post-combustion carbon-capture, requiring the separation of $\mathrm{CO}_{2}$, predominantly from $\mathrm{N}_{2}$ but on a massive scale, has also been suggested. ${ }^{5,6}$ For membranes it is desirable to have good selectivity for one gas over another and for large-

${ }^{a}$ EaStCHEM, School of Chemistry, University of Edinburgh, David Brewster Road, Edinburgh, EH9 3FJ, UK. E-mail: neil.mckeown@ed.ac.uk

${ }^{b}$ Department of Chemistry, Swansea University, College of Science, Grove Building, Singleton Park, Swansea, SA2 8PP, UK

'Institute for Materials and Processes, School of Engineering, The University of Edinburgh, Mayfield Road, Edinburgh EH9 3JL, UK

${ }^{d}$ Institute on Membrane Technology, ITM-CNR, Via P. Bucci 17/C, 87036 Rende, CS, Italy

${ }^{e}$ Center for Macromolecular Science and Engineering, University of Florida, 318 Leigh Hall, P. O. Box 117200, Gainesville, FL 32611-7200, USA

${ }^{f}$ Department of Materials Science and Engineering, The Pennsylvania State University, University Park, PA 16802, USA

$\dagger$ Electronic supplementary information (ESI) available. See DOI: $10.1039 / \mathrm{c} 8 \mathrm{ta} 02601 \mathrm{~g}$ scale separations it is necessary to have very high flux (i.e. permeance or throughput) to minimise the required size of the membrane system. Unfortunately, known highly permeable polymers possess poor selectivity and conversely selective polymers, such as those used presently for commercial applications, possess low permeability and are hence uncompetitive for large-scale gas separations with other technologies such as cryogenic distillation or solvent extraction. ${ }^{7,8}$ The empirical trade-off between the polymer properties of permeability $\left(P_{x}\right)$ and ideal selectivity $\left(P_{x} / P_{y}\right)$ for a given gas pair $(x$ and $y)$ was quantified by Robeson in $1991,{ }^{9}$ and updated in $2008,{ }^{10}$ using the gas permeability data of a large number of polymers. For each gas pair, Robeson identified the upper bound in plots of $\log P_{x}$ versus $\log P_{x} / P_{y}$ and the position of the gas permeability data for a new polymer relative to the 1991 and 2008 upper bounds is used as a universal performance indicator. Theoretical analysis by Freeman suggests that the position of the Robeson upper bound is a direct consequence of the sizesieving nature (i.e. diffusivity selectivity) of the highly rigid glassy polymers, which were used to define it. ${ }^{11,12}$ Consequently, it was suggested that more selective polymers would be obtained by increasing polymer chain rigidity. In addition, ensuring high free volume through increasing inter-chain separation would increase gas diffusivity. Polymers of 
intrinsic microporosity, such as the archetypal PIM-1 (Fig. 1), follow this design concept by using a wholly fused-ring structure to provide rigidity and spiro-centres to ensure a contorted chain structure that cannot pack space efficiently. ${ }^{\mathbf{1 3}, \mathbf{1 4}}$ Gas permeability data for PIMs generally lie over the 1991 upper bounds for most important gas pairs, ${ }^{15-17}$ with data for PIM-1 and PIM-7 being used by Robeson to position 2008 upper bounds for several important gas pairs. ${ }^{\mathbf{1 0}}$ In recent years permeability data for an increasing number of PIMs, particularly those which incorporate rigid bridged bicyclic units such as ethanoanthracene, ${ }^{18-20}$ triptycene, ${ }^{21-25}$ methanopentacene ${ }^{26}$ and Trögers base, ${ }^{18,21}$ have been shown to exceed the 2008 upper bounds due to their enhanced selectivity. Indeed, in 2015 Pinnau et al. proposed that the $\mathrm{O}_{2} / \mathrm{N}_{2}, \mathrm{H}_{2} / \mathrm{N}_{2}$ and $\mathrm{H}_{2} / \mathrm{CH}_{4}$ upper bounds should be updated using permeability data from aged films of triptycene-based PIMs. ${ }^{27}$

In 2012, we reported a preliminary account of a novel PIM in which the spirobisindane (SBI) unit of PIM-1 was replaced with the spirobifluorene (SBF) unit (PIM-SBF-1; Fig. 1).$^{28}$ PIM-SBF-1 demonstrated greater selectivity as compared to PIM-1, without loss of permeability, which placed the data above the 2008 upper bound for the $\mathrm{O}_{2} / \mathrm{N}_{2}, \mathrm{H}_{2} / \mathrm{N}_{2}, \mathrm{H}_{2} / \mathrm{CH}_{4}$ and $\mathrm{CO}_{2} / \mathrm{CH}_{4}$ gas pairs. The improved performance of PIM-SBF- 1 compared to PIM-1 was attributed to the enhanced rigidity of the SBF unit ${ }^{29}$ over that of SBI as demonstrated by molecular dynamics modelling. Work by the group of Pinnau subsequently demonstrated that polyimides of intrinsic microporosity (PIMPIs) incorporating the SBF building unit also have enhanced performance for gas separation relative to SBI-based PIMPIs. ${ }^{30-32}$
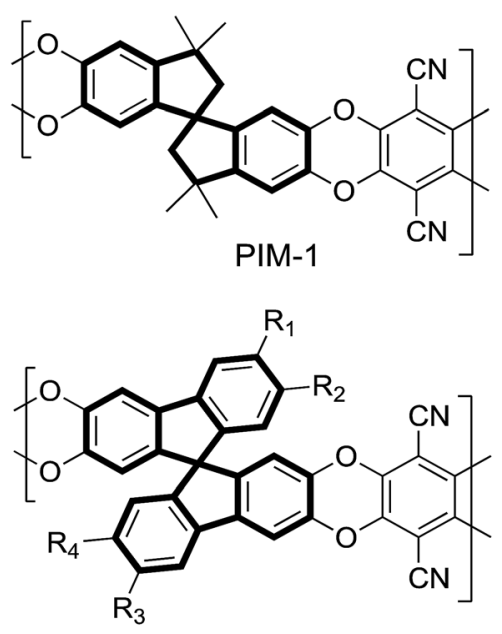

PIM-SBF-1: $\mathrm{R}_{1}, \mathrm{R}_{2}, \mathrm{R}_{3}, \mathrm{R}_{4}=\mathrm{H}$

PIM-SBF-2: $R_{1}, R_{2}, R_{3}, R_{4}=M e$

PIM-SBF-3: $R_{1}, R_{2}=M e, R_{3}, R_{4}=H$

PIM-SBF-4: $\mathrm{R}_{1}=\mathrm{H}, \mathrm{R}_{2}=\mathrm{Me}, \mathrm{R}_{3}=\mathrm{H}, \mathrm{R}_{4}=\mathrm{Me}$

PIM-SBF-5: $R_{1}=H, R_{2}=t-B u, R_{3}=H, R_{4}=t-B u$

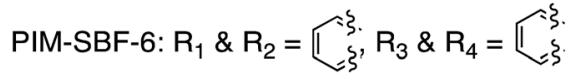

PIM-SBF-7: $R_{1} \& R_{2}=H, R_{3} \& R_{4}=$ 『ל.

Fig. 1 The structures of the spirobisindane-based PIM-1 and the spirobifluorene-based PIM-SBF series.
Following the original report on PIM-SBF-1, a macromolecular packing simulation study predicted that adding four methyl substituents to the SBF unit would result in greater intrinsic microporosity. ${ }^{33}$ Here we report a combined chainpacking simulation and experimental study to confirm this prediction and to investigate further the effect on microporosity and gas permeability by placing simple substituents such as methyl, $t$-butyl and fused benzo units onto the SBF unit of PIMSBF. In addition, data from films aged over prolonged periods of time (>3.5 years) are reported, which suggest that SBF-based PIMs have potential for gas separations involving enhanced diffusivity selectivity via a molecular sieving effect.

\section{Results and discussion}

\section{Synthesis}

A series of seven PIMs, designated PIM-SBF-1 to PIM-SBF-7, was prepared by the aromatic nucleophilic substitution reaction between their respective 2,2',3,3'-tetrahydroxy-9,9-spirobifluorene precursors (1a-g) and 2,3,5,6-tetrafluoroterephthalonitrile as summarised in Scheme 1..$^{13,28}$ The synthesis of the SBF monomers was based on simple adaptations of the well-established route to spirobifluorenes, ${ }^{34}$ involving the addition of the 2-lithio-anion of biphenyl to fluorenone followed by acid-mediated cyclisation. Hence, using a series of substituted 2-bromobiphenyl derivatives (2a-d) as precursors, several 2,3-dimethoxyfluorenones (4a-e) were prepared via a three-step procedure involving treatment with $n$-butyl lithium and addition of $\mathrm{CO}_{2}$ to give the respective carboxylic acids (3a-d), followed by an acid mediated ring closure (i.e. intramolecular acylation). The 2-lithio-anions derived from the same 2-bromobiphenyl derivatives (2a-e) were combined with fluorenones $4 a-e$ to give, after acid treatment, a series of tetramethoxyspirobifluorenes $(\mathbf{5 a}-\mathbf{g})$. Demethylation using boron tribromide gave the SBF monomers $\mathbf{1 a - g}$, which were used in the polymerisation reactions immediately due to their tendency to oxidise on standing.

With the exception of those containing fused benzosubstituents (i.e. PIM-SBFs 6 and 7), the resulting PIM-SBFs all proved soluble in chloroform, facilitating purification by reprecipitation into a non-solvent (methanol) to remove oligomeric impurities. Gel Permeation Chromatography (GPC) of the soluble PIM-SBFs 1-5 confirmed that high molecular mass polymer was achieved in each case with a range of weightaverage molecular mass $\left(M_{\mathrm{w}}\right)$ of $75-110 \times 10^{3} \mathrm{~g} \mathrm{~mol}^{-1}$ relative to polystyrene standards (Table 1 ). The $\mathrm{ESI} \dagger$ gives full experimental details and spectroscopic data for all precursors, monomers and polymers.

\section{Simulation of solid-state packing and prediction of porosity}

Molecular dynamics (MD) simulations were conducted using the LAMMPS software package. ${ }^{35}$ PIM-SBF samples were constructed using the Polymatic simulated polymerization algorithm ${ }^{36}$ and the compression/decompression scheme. ${ }^{37}$ The PIM-SBF structure generation consists of three steps: (1) random packing of respective PIM-SBF 100 repeat monomers into a simulation box under periodic boundary conditions at 


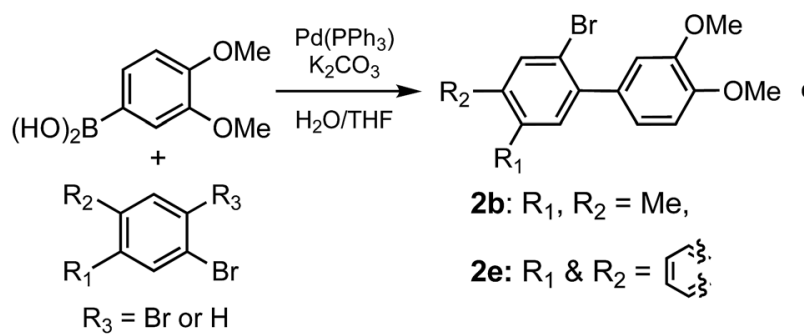<smiles>[R]c1ccc(-c2ccc(OC)c(OC)c2)cc1[R]</smiles>

2a: $\mathrm{R}_{1}, \mathrm{R}_{2}=\mathrm{H}$, 2c: $R_{1}=H, R_{2}=M e$ $\mathrm{R}_{3}=\mathrm{Br}$ or $\mathrm{H}$<smiles>[R]c1cc2c(cc1[R3])-c1cc(OC)c(OC)cc1C2=O</smiles><smiles>[X]c1cc2c(cc1[R])C1(c3cc([R])c([R])cc3-2)c2cc([X])c([X])cc2-c2cc([X])c([R])cc21</smiles><smiles>N#Cc1c(F)c(F)c(C#N)c(F)c1F</smiles><smiles></smiles>

$$
\begin{aligned}
& \text { a: } R_{3}, R_{4}=H \\
& \text { b: } R_{3}, R_{4}=M e \\
& \text { c: } R_{3}=H, R_{4}=M e \\
& \text { d: } R_{3}=H, R_{4}=t-B u \\
& \text { e: } \left.R_{3} \& R_{4}=1\right\}
\end{aligned}
$$

$$
\begin{aligned}
& \text { 5a-g }(X=\mathrm{OMe}) \underset{\text { ii. } \mathrm{H}_{2} \mathrm{O}}{\stackrel{\text { i. } \mathrm{BBr}_{3}}{\longrightarrow}} \text { 1a-g }(X=\mathrm{OH}) \\
& \text { a: } \mathrm{R}_{1}, \mathrm{R}_{2}, \mathrm{R}_{3}, \mathrm{R}_{4}=\mathrm{H} \\
& \text { b: } R_{1}, R_{2}, R_{3}, R_{4}=M e \\
& \text { c: } R_{1}, R_{2}=M e, R_{3}, R_{4}=H \\
& \text { d: } R_{1}=M e, R_{2}=H, R_{3}=M e, R_{4}=H \\
& \text { e: } \mathrm{R}_{1}=t-\mathrm{Bu}, \mathrm{R}_{2}=\mathrm{H}, \mathrm{R}_{3}=t-\mathrm{Bu}, \mathrm{R}_{4}=\mathrm{H} \\
& f: R_{1} \& R_{2}=1 \text { \&. }, R_{3} \& R_{4}=1 \text {, } \\
& g: R_{1}, R_{2}=H, R_{3} \& R_{4}=1 \xi \text {. }
\end{aligned}
$$

Scheme 1 The synthesis of PIM-SBFs 1-7 (see Section 2 of the ESI† for details)

a low arbitrary density of $0.3-0.4 \mathrm{~g} \mathrm{~cm}^{-3}$, (2) polymerization via Polymatic simulated polymerization algorithm and (3) compression/decompression of the polymerized sample, '21steps' to generate a final simulation box at relevant experimental conditions. ${ }^{37}$ Details of the methodology of the chain packing simulations, structural analysis and gas adsorption simulation are given in Section 1 of the ESI. $\dagger^{38}$

\section{Gas adsorption and gas transport properties}

The powdered form of all of the PIM-SBFs, obtained from precipitation, adsorb a large amount of nitrogen $\left(\mathrm{N}_{2}\right)$ at $77 \mathrm{~K}$. Analysis of the $\mathrm{N}_{2}$ adsorption isotherms (Fig. S5-10†) gives apparent Brunauer-Emmett-Teller (BET) surface areas $\left(\mathrm{SA}_{\mathrm{BET}}\right)$

\begin{tabular}{|c|c|c|c|c|c|c|c|c|}
\hline PIM-SBF & 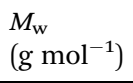 & $M_{\mathrm{w}} / M_{\mathrm{n}}$ & $\begin{array}{l}\mathrm{SA}_{\mathrm{BET}}{ }^{a} \\
\left(\mathrm{~m}^{2} \mathrm{~g}^{-1}\right)\end{array}$ & $\begin{array}{l}\mathrm{SA}_{\mathrm{BET}} \text { model } \\
\left(\mathrm{m}^{2} \mathrm{~g}^{-1}\right)\end{array}$ & $\begin{array}{l}V_{\text {Total }}^{b} \\
\left(\mathrm{ml} \mathrm{g}^{-1}\right)\end{array}$ & $\begin{array}{l}V_{\mathrm{M}}^{c} \\
\left(\mathrm{ml} \mathrm{g}^{-1}\right)\end{array}$ & $\begin{array}{l}\mathrm{CO}_{2} \text { uptake }^{d} \\
\left(\mathrm{mmol} \mathrm{g}^{-1}\right)\end{array}$ & $\begin{array}{l}\mathrm{CO}_{2} \text { uptake model } \\
\left(\mathrm{mmol} \mathrm{g}^{e-1}\right)\end{array}$ \\
\hline 1 & 89000 & 2.3 & 803 & 760 & 0.71 & 0.28 & 2.4 & 3.8 \\
\hline 2 & 95000 & 2.3 & 938 & 950 & 0.69 & 0.33 & 3.0 & 4.2 \\
\hline 3 & 76000 & 1.8 & 794 & - & 0.54 & 0.28 & 2.6 & - \\
\hline 4 & 75000 & 1.9 & 752 & - & 0.54 & 0.28 & 2.8 & - \\
\hline 5 & 110000 & 2.4 & 882 & 980 & 0.70 & 0.31 & 2.5 & 3.6 \\
\hline 6 & - & - & 768 & 800 & 0.45 & 0.26 & 2.8 & 4.1 \\
\hline 7 & - & - & 727 & 820 & 0.48 & 0.26 & 2.5 & 4.3 \\
\hline
\end{tabular}
within the range of $727-938 \mathrm{~m}^{2} \mathrm{~g}^{-1}$ (Table 1), with the value for PIM-SBF-2 being similar to that from PIMs possessing the highest $\mathrm{SA}_{\mathrm{BET}}$ for solution processable polymers. ${ }^{\mathbf{1 8 2} 4}$ It is notable that the BET value for PIM-SBF-2 calculated from the simulation study is very similar to the apparent value measured directly from $\mathrm{N}_{2}$ isotherms and supports the prediction that methyl substituents will enhance intrinsic microporosity by increasing the inter-chain distance. ${ }^{33}$ Both simulation and experimental analysis of PIM-SBF-5 confirm that microporosity is also enhanced by the use of $t$-butyl substituents. Overall, there is good correlation between the predicted and experimentally

Table 1 Molecular mass and gas adsorption properties of PIM-SBFs 1-7

${ }^{a}$ BET surface area calculated from $\mathrm{N}_{2}$ adsorption isotherm obtained at $77 \mathrm{~K} .{ }^{b}$ Total pore volume estimated from $\mathrm{N}_{2}$ uptake at $P / P_{\mathrm{o}}=0.98$. ${ }^{c}$ Micropore volume estimated from $\mathrm{N}_{2}$ uptake at $P / P_{\mathrm{o}}=0.05 .{ }^{d} \mathrm{CO}_{2}$ adsorption at 1 bar and $273 \mathrm{~K} .{ }^{e} \mathrm{CO}_{2}$ uptake calculated from packing model appears to overestimate experimental uptake by a factor of 1.5 as reported for previous studies. 


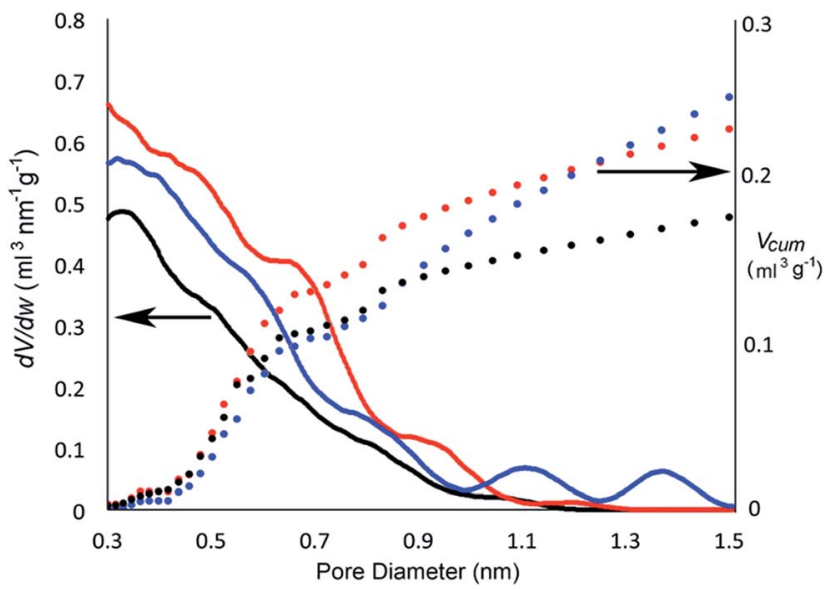

Fig. 2 Pore size distribution (dV/dw) of PIM-SBF-1 (black line), PIMSBF-2 (red line) and PIM-SBF-5 (blue line) calculated from the chain packing simulations plotted together with the DFT cumulative pore volume $\left(V_{\text {cum }}\right)$ of PIM-SBF-1 (black circles), PIM-SBF-2 (red circles) and PIM-SBF-5 (blue circles) calculated from $\mathrm{CO}_{2}$ adsorption data using DFT.

determined BET surface areas for all PIM-SBFs (i.e. within $100 \mathrm{~m}^{2} \mathrm{~g}^{-1}$ ), which is within the range of reported experimental values of the BET surface area of PIM-1 quoted in the literature $\left(720-870 \mathrm{~m}^{2} \mathrm{~g}^{-1}\right)$ caused by the variation in $\mathrm{N}_{2}$ adsorption isotherms at $77 \mathrm{~K} .{ }^{38}$ Micropore size distributions calculated from $\mathrm{CO}_{2}$ adsorption at $273 \mathrm{~K}$ for PIM-SBF-1, PIM-SBF-2 and PIM-SBF-5 (Fig. S11†) using DFT correlate well with those calculated from the chain packing simulations (Fig. 2 and $\mathrm{S} 12 \dagger$ ).

Significantly, both PIM-SBF-2 and PIM-SBF-5 possess greater microporosity than PIM-SBF-1 but with a clear difference in pore size distribution so that PIM-SBF-2 has a greater contribution from ultramicropores $(<0.7 \mathrm{~nm})$ whereas PIM-SBF-5 has greater pore volume from larger micropores $(>1.0 \mathrm{~nm})$.

\section{Gas permeability}

Simple solvent casting from chloroform solution allowed the fabrication of optically clear and robust films of PIM-SBFs 1-5, of $\sim 100 \mu \mathrm{m}$ thickness, suitable for gas permeability studies. The pure gas permeabilities of PIM-SBFs 1-5, which had first been soaked in methanol and then dried in air at room temperature for $24 \mathrm{~h}$, are given in Table 2. Methanol treatment has been shown previously to reverse the effects of physical ageing for glassy ultra-permeable polymers and it also removes the last residues of casting solvent. ${ }^{16,39,40}$ In addition, methanol treatment allows a direct comparison between the gas permeabilities of different polymers prior to ageing. The equivalent data for a freshly methanol treated film of PIM-1 of similar thickness, measured under identical conditions to those of the PIM-SBFs, are also provided in Table 2 for comparison.

For each methanol treated PIM-SBF the order of gas permeabilities is $\mathrm{CO}_{2}>\mathrm{H}_{2}>\mathrm{O}_{2}>\mathrm{He}>\mathrm{CH}_{4}>\mathrm{N}_{2}$, which is the same as that for PIM-1. As noted previously, ${ }^{28}$ whilst the values for gas permeabilities are broadly similar for PIM-1 and PIM$\mathrm{SBF}-1$ for gases with smaller kinetic diameters (i.e. $\mathrm{He}=2.69$; $\mathrm{H}_{2}=2.8 ; \mathrm{CO}_{2}=3.3 ; \mathrm{O}_{2}=3.46 \AA$ ) , those for larger molecules (i.e. $\left.\mathrm{N}_{2}=3.64 ; \mathrm{CH}_{4}=3.87 \AA\right)$ are smaller $(>30 \%)$ resulting in a significant enhancement of ideal selectivities. As noted previously, ${ }^{28}$ this places the data for PIM-SBF-1 above the 2008 upper bound for the $\mathrm{O}_{2} / \mathrm{N}_{2}, \mathrm{H}_{2} / \mathrm{N}_{2}, \mathrm{~N}_{2} / \mathrm{CH}_{4}$ and $\mathrm{CO}_{2} / \mathrm{CH}_{4}$ gas pairs and can be directly ascribed to the greater rigidity of the SBF units as compared to SBI units of PIM-1. It is evident from the data for PIM-SBFs 2-5 that placing methyl or $t$-butyl substituents onto the SBF unit causes a moderate to large increase in gas permeabilities relative to those of both PIM-1 and PIM-SBF-1. This is consistent with the conclusion derived from predictive packing simulations ${ }^{33}$ and experimental gas adsorption, discussed above, that methyl groups help to increase the inter-chain separation distance and generate greater intrinsic microporosity. The order of increasing gas permeability is PIM-SBF-1 (0 Me) < PIM-SBF-4 $\approx$ PIM-SBF-3 (both $2 \mathrm{Me}$ ) < PIM-SBF-5 (6 Me) < PIM-SBF-2 (4 Me). The gas permeabilities for PIM-SBF-2 and PIM-SBF-5 are significantly higher than for all reported PIMs with the exception of PIM-1, ${ }^{42}$ which is slightly less permeable than PIM-SBF-2 but more so than PIM-SBF-5, and the recently reported PIM-TMN-Trip, ${ }^{24}$ the latter deriving its exceptionally high permeability from its

Table 2 Ideal gas permeabilities of freshly methanol treated and aged films of PIM-SBFs $1-5$ measured at $25^{\circ} \mathrm{C}$ with data for PIM-1 39,41 given for comparison

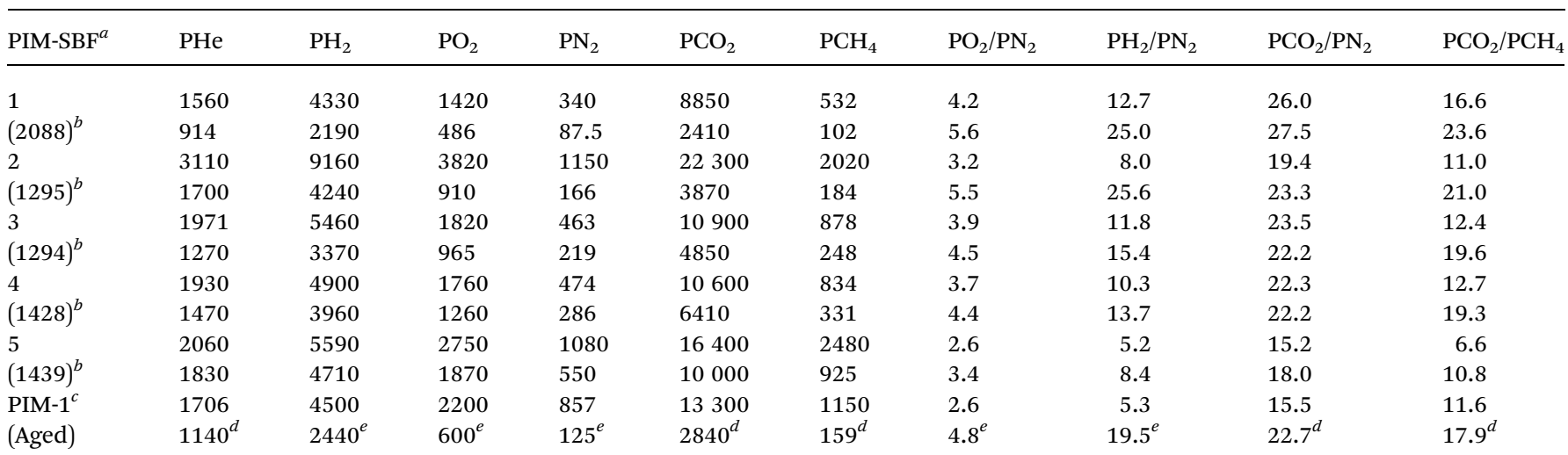

${ }^{a}$ Film thickness: PIM-SBF- $1=80 \mu \mathrm{m}$, PIM-SBF- $2=115 \mu \mathrm{m}$, PIM-SBF- $3=120 \mu \mathrm{m}$, PIM-SBF- $4=120 \mu \mathrm{m}$, PIM-SBF- $5=98 \mu \mathrm{m} .{ }^{b}$ Aged for the number of days given in parentheses. ${ }^{c}$ PIM-1 (freshly MeOH treated) ${ }^{39}=128 \mu \mathrm{m} .{ }^{d}$ PIM-1 (aged 1380 days) $=102 \mu \mathrm{m} .{ }^{41}{ }^{e}$ PIM-1 (aged 1200 days) $=110 \mu \mathrm{m} .{ }^{39}$ 
unique $2 \mathrm{D}$ chain structure. In addition, there are several polyacetylenes with high gas permeabilities, such as the ultrapermeable poly(trimethylsilylpropyne) (PTMSP), when freshly treated with methanol, although with much lower selectivities relative to the PIMs. ${ }^{43}$ For PIM-SBFs $2-4$, in which the methyl groups are attached directly to the SBF unit, the selectivity enhancement noted for PIM-SBF-1 over PIM-1 is maintained providing data points, which are of a similar distance above the 2008 Robeson upper bounds for the $\mathrm{O}_{2} / \mathrm{N}_{2}, \mathrm{H}_{2} / \mathrm{N}_{2}, \mathrm{CO}_{2} / \mathrm{N}_{2}$ and $\mathrm{CO}_{2} / \mathrm{CH}_{4}$ gas pairs (Fig. 3).

This is consistent with the high concentration of ultramicropores $(<0.7 \mathrm{~nm})$ suggested by chain-packing simulation and analysis of gas adsorption data for PIM-SBF-2 (Fig. 2). Ultramicropores, being of similar size to the kinetic diameter of gas molecules, are responsible for selective gas transport. In contrast, the relatively low selectivity of PIM-SBF-5 can be ascribed to a broader pore size distribution with a greater concentration of larger, less selective, micropores $(>1.0 \mathrm{~nm})$ (Fig. 2). In addition, the $t$-butyl substituents of PIM-SBF-5 will be relatively free to undergo thermal motions so that they may act as molecular turnstiles facilitating the transport of larger gas molecules such as $\mathrm{N}_{2}$ and $\mathrm{CH}_{4}$.

\section{Extended ageing studies}

Physical ageing (i.e. loss of free volume over time) is a general feature of glassy polymers. For example, data for PIM-1 shows that after an extended period of 1360 days the value for $\mathrm{PO}_{2}$ falls to 317 Barrer but with a corresponding increase in selectivity of $\mathrm{PO}_{2} / \mathrm{PN}_{2}=5.0{ }^{41}$ Ageing studies were conducted on films of all of the PIM-SBFs with gas permeability measurements taken after at least 1200 days to allow for a direct comparison with the previous PIM-1 ageing study ${ }^{\mathbf{4 1}}$ (Table 2). On extended ageing of PIM-SBF-1-4 the order of gas permeability becomes $\mathrm{H}_{2}>\mathrm{CO}_{2}>$ $\mathrm{He}>\mathrm{O}_{2}>\mathrm{CH}_{4}>\mathrm{N}_{2}$, which is more conventional for glassy
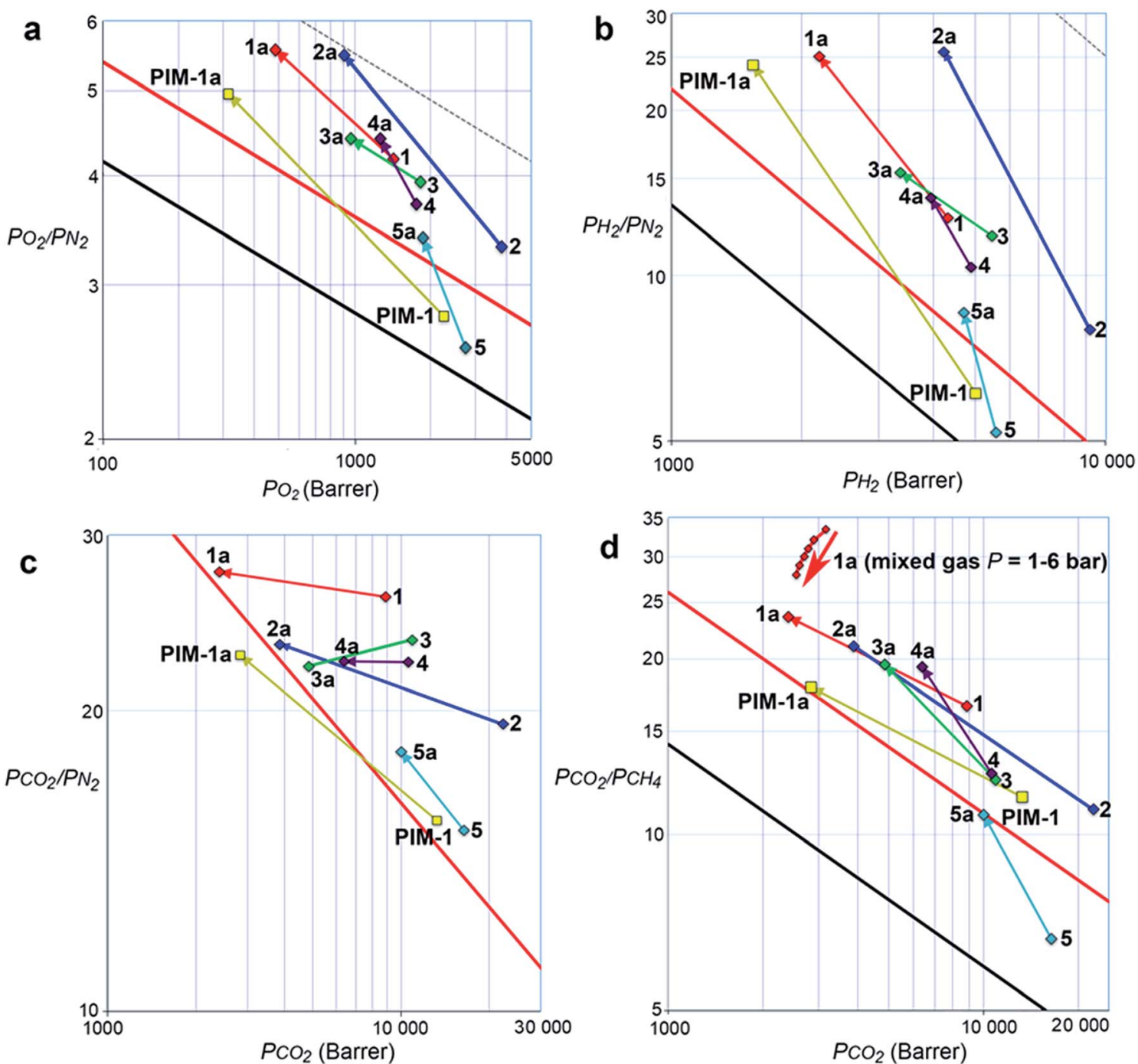

Fig. 3 Robeson plots for the (a) $\mathrm{O}_{2} / \mathrm{N}_{2}$, (b) $\mathrm{H}_{2} / \mathrm{N}_{2}$, (c) $\mathrm{CO}_{2} / \mathrm{N}_{2}$ and (d) $\mathrm{CO}_{2} / \mathrm{CH}_{4}$ gas pairs showing the position of the gas permeability data for PIM-SBFs 1-5 and that of PIM-1. Data from films aged for $>3.5$ years (e.g. 2a) are joined by an arrow to those of the freshly methanol treated films to form ageing trend-lines. Upper bounds are represented by black (1991), red (2008) and dotted (2015) lines. $\mathrm{Mixed} \mathrm{CO}_{2} / \mathrm{CH}_{4}$ data at pressures of 1-6 bar for the film of PIM-SBF-1 aged for 2088 days are also plotted with red arrow indicating increasing pressure. 
polymers. When the data from aged films are placed on the appropriate Robeson plot (Fig. 3), it can be observed that PIMSBF-2 ages at an approximately similar rate relative to both PIM-1 and PIM-SBF-1 with loss of permeability combined with a significant increase in selectivity. Interestingly, for the $\mathrm{O}_{2} / \mathrm{N}_{2}$ and $\mathrm{H}_{2} / \mathrm{N}_{2}$ gas pairs these trend lines are approximately parallel and are steeper in gradient than the Robeson upper bounds. For these two gas pairs selectivity is based on differences in gas diffusivity, therefore, size-selectivity is being enhanced beyond that expected by the standard polymer permeability-selectivity trade-off. The pore structure of PIM-SBF-1-4 translates into a very steep correlation of the diffusion coefficient with the gas diameter, highlighting the strong size-selectivity of these polymers particularly after ageing (Fig. 4a). The slope is highest for the less permeable and more selective PIM-SBF-1 and lowest for most permeable and less selective PIM-SBF-5, showing that the permselectivity is closely related to the diffusion selectivity. The steeper slope, and thus increased size-sieving behaviour after aging, is an indication for a denser packing and lower free volume of the aged sample with respect to the $\mathrm{MeOH}$ treated sample (Fig. 4b).

Hence, ageing is preferentially reducing larger micropores within the PIM-SBFs. Notably, the data for PIM-SBF-2 after ageing for 1295 days $\left(\mathrm{PO}_{2}=910\right.$ Barrer; $\left.\mathrm{PO}_{2} / \mathrm{PN}_{2}=5.5\right)$ is very close to the proposed 2015 upper bound for $\mathrm{O}_{2} / \mathrm{N}_{2}$ (Fig. 3a). ${ }^{27}$

In contrast, for the $\mathrm{CO}_{2} / \mathrm{N}_{2}$ gas pair the ageing trend line for each of PIM-SBF-1-4 are at a much shallower gradient than the 2008 Robeson upper bound (Fig. 3c), which can be explained by $\mathrm{CO}_{2} / \mathrm{N}_{2}$ separation being dominated by solubility selectivity. $\mathrm{CO}_{2}$ solubility is correlated to the amount of free volume within the polymer which is lost on ageing. For the $\mathrm{CO}_{2} / \mathrm{CH}_{4}$ gas pair there is a contribution to selectivity from both gas solubility and diffusivity and the ageing trend lines for PIM-SBF-1-4 are well above and roughly parallel to the 2008 Robeson upper bound (Fig. 3d). For this gas pair the data for aged film of PIM-SBF-1 is particularly impressive $\left(\mathrm{PCO}_{2}=2410\right.$ Barrer; $\left.\mathrm{PCO}_{2} / \mathrm{PCH}_{4}=24\right)$.

The ageing of PIM-SBF-5 is anomalously slow relative to that of the other PIM-SBFs with large values of gas permeability demonstrated almost four years after methanol treatment (e.g. $\mathrm{PCO}_{2}>10000$ Barrer) and the original $\mathrm{CO}_{2}>\mathrm{H}_{2}>\mathrm{O}_{2}>\mathrm{He}>\mathrm{CH}_{4}$ $>\mathrm{N}_{2}$ order of gas permeabilities is maintained (Table 2; Fig. 3). Remarkably, the values of gas permeabilities for this aged film of PIM-SBF-5 are greater than those of freshly methanol treated PIM-SBF-1. Therefore, the bulky $t$-butyl groups of PIM-SBF-5 appear better than the methyl substituents of PIM-SBFs 2-4 at maintaining the distance between polymer chains during ageing.

Ultimately, for practical membrane application in gas separations, the PIM selective layer would be the thin skin on a hollow fibre or a thin film within a composite membrane. It is well-established that physical ageing of polymers, particularly those of high free volume, is much more rapid in thin films. ${ }^{\mathbf{4 5 , 4 6}}$ A recent study on PIM-1 hollow fibres ${ }^{47}$ estimates that the gas permeability and selectivity of the thin selective layer $(\sim 3 \mu \mathrm{m}$; $\mathrm{PO}_{2}=200$ Barrer; $\mathrm{PO}_{2} / \mathrm{PN}_{2}=4.6$ ) are similar to those of a thick film $(102 \mu \mathrm{m})$ that had been aged for 1360 days. ${ }^{41}$ The long-term ageing study of the PIM-SBFs suggest that, with the exception of

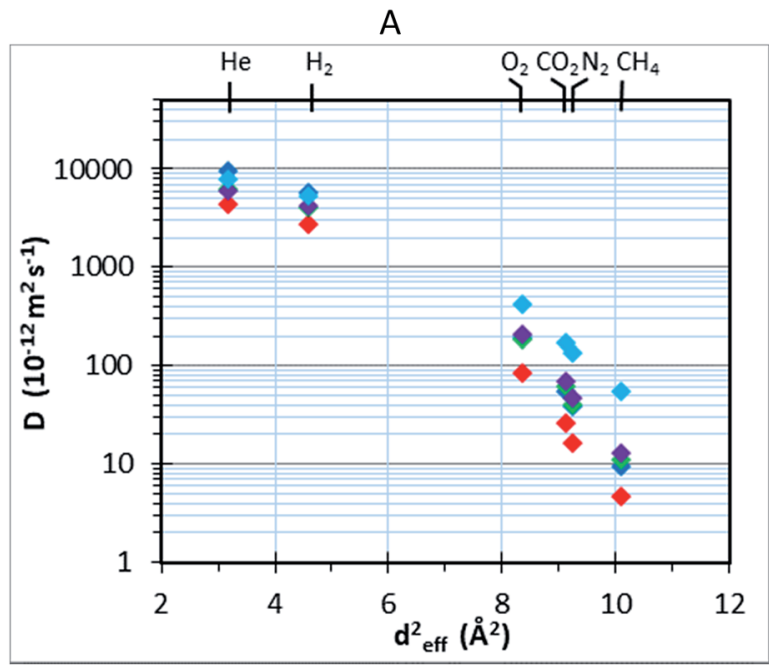

B

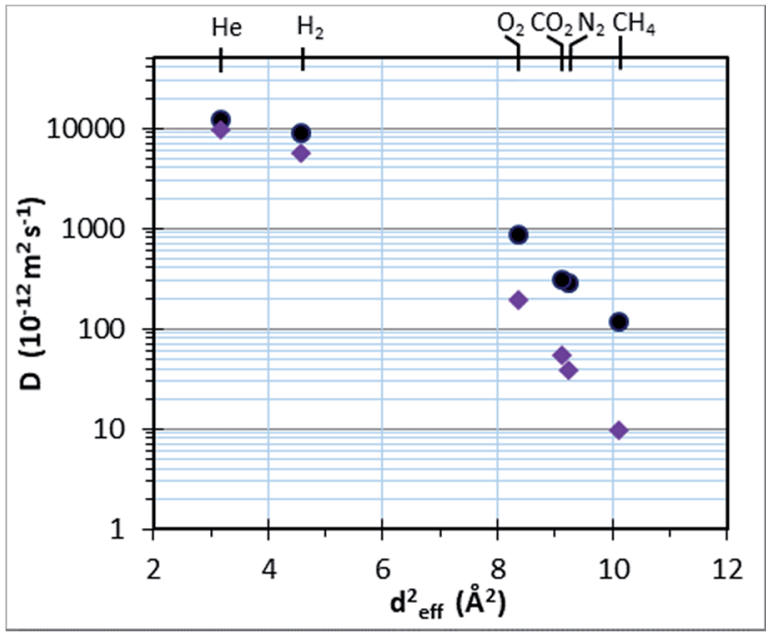

Fig. 4 Correlation of the diffusion coefficient with the square of the effective gas diameter for aged samples $(A)^{44}$ PIM-SBF-1 $(\diamond)$, PIM-SBF$2(\diamond), \operatorname{PIM}-\mathrm{SBF}-3(\diamond), \mathrm{PIM}-\mathrm{SBF}-4(\diamond), \mathrm{PIM}-\mathrm{SBF}-5(\diamond)$. Effect of sample history for PIM-SBF-4 (B) $\mathrm{MeOH}$ treated sample (•) and aged sample ( $\diamond)$

PIM-SBF-5, they age similarly to PIM-1 with commensurate increases in selectivities (Fig. 3). Therefore, for thin films of PIM-SBF-2, it can be estimated that the separation of important gas pairs based on diffusivity selectivity (e.g. $\left.\mathrm{O}_{2} / \mathrm{N}_{2}\right)$ would approach those of commercial polymer membranes (e.g. $\mathrm{PO}_{2} /$ $\mathrm{PN}_{2}>5.5$ ) but with much higher permeance ( $\sim$ three times that expected for PIM-1).

\section{Mixed gas permeation}

Mixed gas permeation measurements with $\mathrm{CO}_{2} / \mathrm{CH}_{4}$ were carried out both across a total pressure range of 1-6 bar using a $35 / 65 \mathrm{vol} \%$ mixture and a $\mathrm{CO}_{2}$ feed concentration of $10-50 \%$ in $\mathrm{CH}_{4}$ at 3 bar for two representative aged samples: the most selective sample, PIM-SBF-1 aged over 2088 days, and the most permeable sample, PIM-SBF-5 aged for 1439 days (Fig. 5).

For the mixed gas measurements PIM-SBF-1 and PIM-SBF-5 both maintain excellent gas permeability to give values that are 
A

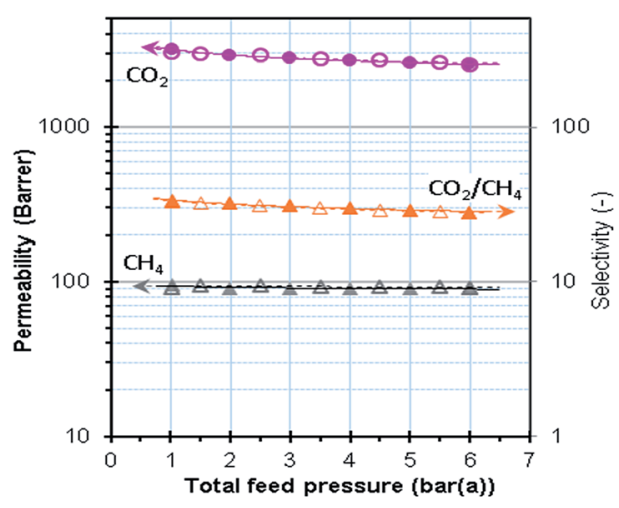

C

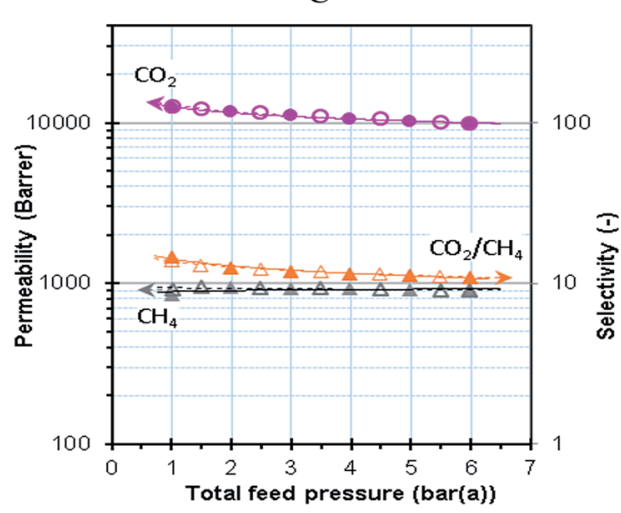

B

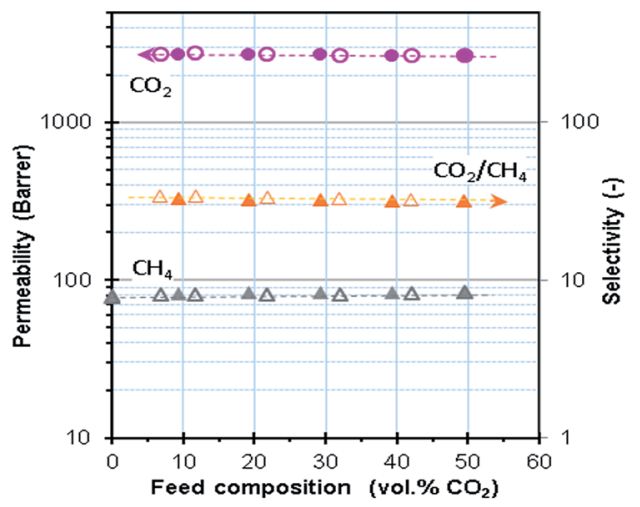

$\mathrm{D}$

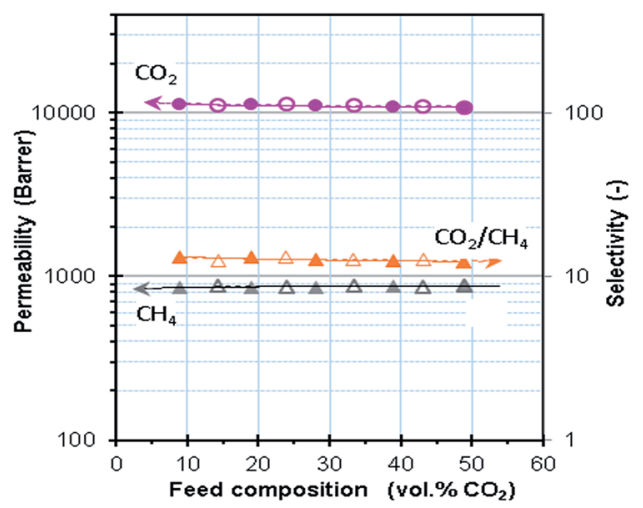

Fig. 5 Mixed gas separation performance of aged PIM-SBF-1 (A) and aged PIM-SBF-5 (C) as a function of the feed pressure for the $\mathrm{CO}_{2} / \mathrm{CH}_{4}$ (35/65 vol\%) mixture and performance of PIM-SBF-1 (B) and PIM-SBF-5 (D) as a function of the feed composition for the $\mathrm{CO}_{2} / \mathrm{CH}_{4}$ mixture at

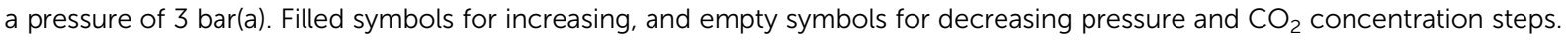

similar to the ideal values measured with pure gases. In both films the $\mathrm{CO}_{2}$ permeability and $\mathrm{CO}_{2} / \mathrm{CH}_{4}$ selectivity decrease about $20 \%$ upon a pressure increase from 1 to 6 bar, while the $\mathrm{CH}_{4}$ permeability remains virtually constant. On the other hand, at a feed pressure of 3 bar the transport parameters of PIM-SBF- 5 are independent of the gas composition in the range of $10-50 \% \mathrm{CO}_{2}$, which is good for a stable operation of a membrane separation plant under variable feed conditions, for instance in the case of biogas separation. At a pressure of 1 bar, the permselectivity is substantially higher than the ideal value and the points lie in a more favourable region of the Robeson diagram (Fig. 3d). At higher pressures, they converge close to the ideal values measured from pure gases.

\section{Conclusions}

Both methyl (PIM-SBF-2-4) and $t$-butyl substituents (PIM-SBF-5) attached to the SBF unit increase intrinsic microporosity as demonstrated by chain packing simulations, and by analysis of both gas adsorption data and gas permeability of the PIM-SBF series. However, these two substituents generate a significant difference in pore size distribution, as predicted by packing simulation, that has a marked effect on the ideal gas selectivity of these polymers. Furthermore, these differences appear to be accentuated on ageing over an extended period with good selectivities being obtained. Indeed, the excellent performance of aged PIM-SBF-1 in mixed gas $\mathrm{CO}_{2} / \mathrm{CH}_{4}$ separation experiments $\left(\mathrm{PCO}_{2}>2000\right.$ Barrer; $\left.\mathrm{PCO}_{2} / \mathrm{PCH}_{4}>25\right)$ suggests its use might allow significant reductions to the size of current membrane systems for industrially relevant gas separations, such as natural gas or biogas upgrading.

\section{Conflicts of interest}

There are no conflicts of interest to declare.

\section{Acknowledgements}

The research leading to these results has received funding from the EU FP7 Framework Program under grant agreement no. 608490 , project $\mathrm{M}^{4} \mathrm{CO}_{2}$ and from the EPSRC (UK) grant numbers $\mathrm{EP} / \mathrm{M} 01486 \mathrm{X} / 1$ and EP/K008102/2. This work was also supported by the US National Science Foundation (DMR-1604376). High-performance computational resources were provided by the University of Florida Research Computing and the Research Computing and Cyberinfrastructure unit at Pennsylvania State University. Paola Bernardo and Gabriele Clariza are gratefully acknowledged for some preliminary pure gas permeation measurements and Marek Lanč for his help in developing the mixed gas separation system. 


\section{References}

1 R. W. Baker and B. T. Low, Macromolecules, 2014, 47, 69997013.

2 P. Bernardo, E. Drioli and G. Golemme, Ind. Eng. Chem. Res., 2009, 48, 4638-4663.

3 M. Galizia, W. S. Chi, Z. P. Smith, T. C. Merkel, R. W. Baker and B. D. Freeman, Macromolecules, 2017, 50, 7809-7843.

4 Y. Yampolskii, Macromolecules, 2012, 45, 3298-3311.

5 S. F. Wang, X. Q. Li, H. Wu, Z. Z. Tian, Q. P. Xin, G. W. He, D. D. Peng, S. L. Chen, Y. Yin, Z. Y. Jiang and M. D. Guiver, Energy Environ. Sci., 2016, 9, 1863-1890.

6 M. C. Ferrari, D. Bocciardo and S. Brandani, Green Energy \& Environment, 2016, 1, 211-221.

7 P. M. Budd and N. B. McKeown, Polym. Chem., 2010, 1, 63-68. 8 H. B. Park, J. Kamcev, L. M. Robeson, M. Elimelech and B. D. Freeman, Science, 2017, 356, 1137.

9 L. M. Robeson, J. Membr. Sci., 1991, 62, 165-186.

10 L. M. Robeson, J. Membr. Sci., 2008, 320, 390-400.

11 L. M. Robeson, B. D. Freeman, D. R. Paul and B. W. Rowe, J. Membr. Sci., 2009, 341, 178-185.

12 B. D. Freeman, Macromolecules, 1999, 32, 375-380.

13 P. M. Budd, E. S. Elabas, B. S. Ghanem, S. Makhseed, N. B. McKeown, K. J. Msayib, C. E. Tattershall and D. Wang, Adv. Mater., 2004, 16, 456-459.

14 M. Heuchel, D. Fritsch, P. M. Budd, N. B. McKeown and D. Hofmann, J. Membr. Sci., 2008, 318, 84-99.

15 P. M. Budd, K. J. Msayib, C. E. Tattershall, B. S. Ghanem, K. J. Reynolds, N. B. McKeown and D. Fritsch, J. Membr. Sci., 2005, 251, 263-269.

16 P. M. Budd, N. B. McKeown, B. S. Ghanem, K. J. Msayib, D. Fritsch, L. Starannikova, N. Belov, O. Sanfirova, Y. Yampolskii and V. Shantarovich, J. Membr. Sci., 2008, 325, 851-860.

17 S. Thomas, I. Pinnau, N. Du and M. D. Guiver, J. Membr. Sci., 2009, 333, 125-131.

18 M. Carta, R. Malpass-Evans, M. Croad, Y. Rogan, J. C. Jansen, P. Bernardo, F. Bazzarelli and N. B. McKeown, Science, 2013, 339, 303-307.

19 Y. Rogan, L. Starannikova, V. Ryzhikh, Y. Yampolskii, P. Bernardo, F. Bazzarelli, J. C. Jansen and N. B. McKeown, Polym. Chem., 2013, 4, 3813-3820.

20 E. Tocci, L. De Lorenzo, P. Bernardo, G. Clarizia, F. Bazzarelli, N. B. McKeown, M. Carta, R. Malpass-Evans, K. Friess, K. Pilnacek, M. Lanc, Y. P. Yampolskii, L. Strarannikova, V. Shantarovich, M. Mauri and J. C. Jansen, Macromolecules, 2014, 47, 7900-7916.

21 M. Carta, M. Croad, R. Malpass-Evans, J. C. Jansen, P. Bernardo, G. Clarizia, K. Friess, M. Lanc and N. B. McKeown, Adv. Mater., 2014, 26, 3526-3531.

22 B. S. Ghanem, R. Swaidan, X. Ma, E. Litwiller and I. Pinnau, Adv. Mater., 2014, 26, 6696-6700.

23 R. Swaidan, M. Al-Saeedi, B. Ghanem, E. Litwiller and I. Pinnau, Macromolecules, 2014, 47, 5104-5114.
24 I. Rose, C. G. Bezzu, M. Carta, B. Comesana-Gandara, E. Lasseuguette, M. C. Ferrari, P. Bernardo, G. Clarizia, A. Fuoco, J. C. Jansen, K. E. Hart, T. P. Liyana-Arachchi, C. M. Colina and N. B. McKeown, Nat. Mater., 2017, 16, 932-937.

25 I. Rose, M. Carta, R. Malpass-Evans, M.-C. Ferrari, P. Bernardo, G. Clarizia, J. C. Jansen and N. B. McKeown, ACS Macro Lett., 2015, 4, 912-915.

26 R. Williams, L. A. Burt, E. Esposto, J. C. Jansen, E. Tocci, C. Rizzuto, M. Lanc, M. Carta and N. B. McKeown, J. Mater. Chem. A, 2018, 6, 5661-5667.

27 R. Swaidan, B. Ghanem and I. Pinnau, ACS Macro Lett., 2015, 4, 947-951.

28 C. G. Bezzu, M. Carta, A. Tonkins, J. C. Jansen, P. Bernardo, F. Bazzarelli and N. B. McKeown, Adv. Mater., 2012, 24, 5930.

29 V. Lukes, R. Solc, F. Milota, J. Sperling and H. F. Kauffmann, Chem. Phys., 2008, 349, 226-233.

30 X. Ma, B. Ghanem, O. Salines, E. Litwiller and I. Pinnau, ACS Macro Lett., 2015, 4, 231-235.

31 X. Ma, O. Salinas, E. Litwiller and I. Pinnau, Macromolecules, 2013, 46, 9618-9624.

32 X. Ma, O. Salinas, E. Litwiller and I. Pinnau, Polym. Chem., 2014, 5, 6914-6922.

33 K. E. Hart, J. M. Springmeier, N. B. McKeown and C. M. Colina, Phys. Chem. Chem. Phys., 2013, 15, 20161-20169.

34 R. G. Clarkson and M. Gomberg, J. Am. Chem. Soc., 1930, 52, 2881-2891.

35 S. Plimpton, J. Comput. Phys., 1995, 117, 1.

36 L. J. Abbott, K. E. Hart and C. M. Colina, Theor. Chem. Acc., 2013, 132, 1334.

37 G. S. Larsen, P. Lin, K. E. Hart and C. M. Colina, Macromolecules, 2011, 44, 6944-6951.

38 M. Minelli, D. R. Paul and G. C. Sarti, J. Membr. Sci., 2017, 540, 229-242.

39 P. Bernardo, E. Bazzarelli, F. Tasselli, G. Clarizia, C. R. Mason, L. Maynard-Atem, P. M. Budd, M. Lanc, K. Pilnacek, O. Vopicka, K. Friess, D. Fritsch, Y. P. Yampolskii, V. Shantarovich and J. C. Jansen, Polymer, 2017, 113, 283-294.

40 K. Pilnáček, O. Vopička, M. Lanč, M. Dendisová, M. Zgažar, P. M. Budd, M. Carta, R. Malpass-Evans, N. B. McKeown and K. Friess, J. Membr. Sci., 2016, 520, 895-906.

41 R. Swaidan, B. Ghanem, E. Litwiller and I. Pinnau, Macromolecules, 2015, 48, 6553-6561.

42 J. Zhang, H. Kang, J. Martin, S. Zhang, S. Thomas, T. C. Merkel and J. Jin, Chem. Commun., 2016, 52, 6553-6556. 43 Y. Yampolskii, Polym. Rev., 2017, 57, 200-212.

44 V. Teplyakov and P. Meares, Gas Sep. Purif., 1990, 4, 66-74. 45 R. R. Tiwari, Z. P. Smith, H. Q. Lin, B. D. Freeman and D. R. Paul, Polymer, 2014, 55, 5788-5800.

46 R. R. Tiwari, J. Y. Jin, B. D. Freeman and D. R. Paul, J. Membr. Sci., 2017, 537, 362-371.

47 M. L. Jue, V. Breedveld and R. P. Lively, J. Membr. Sci., 2017, 530, 33-41. 